\title{
Compliance with depot medication and readmission to hospital of patients with schizophrenia
}

\author{
Justin Gardner and Oscar Hill
}

This paper examines the relationship between non-
compliance with depot medication and readmission
to hoepltal of patients with schizophrenia. Non-
compliance is aseociated with being of no flxed obode
and readmission under the Mental Heatth Act. The
mertts of a community superviston order are discussed.

There is an inescapable body of evidence, from both sides of the Atlantic, that compliance with medication reduces relapse and readmission in schizophrenia (Leff \& Wing, 1971; Green, 1988). The gradual decrease in hospital beds has brought with it the challenge of maintaining large numbers of patients in the community. This has led to considerable recent debate on the pitfalls of community treatment and the need for some form of compulsory supervision order (Bluglass, 1992, 1993; Turner, pages 657-659).

Although it is well known that compliance with medication reduces relapse and readmission, there is a dearth of literature comparing the characteristics of compliant and non-compliant patients requiring rehospitalisation. This study examines schizophrenic patients who relapse and its relationship to compliance and noncompliance with depot medication.

\section{The study}

St Luke's Woodside Hospital is five miles from central London and serves parts of the innerLondon boroughs of Camden, Islington and Westminster. The hospital has 59 acute beds. The population served is characterised by homelessness and multiethnicity. Many patients are not registered with a GP and few patients live in a family setting. Community care provision is often frustrated by the transient nature of the population served.

All patients admitted between 1 January and 30 June 1993 with a clinical diagnosis of schizophrenia recorded in the case-notes were studied.
Table 1. Accommodation prior to admission

\begin{tabular}{llll}
\hline & $\begin{array}{l}\text { Compliant } \\
\text { with depot } \\
(n=11)\end{array}$ & $\begin{array}{l}\text { Non-compliant } \\
\text { with depot } \\
(n=23)\end{array}$ & $\begin{array}{l}\text { Total } \\
\text { sample } \\
(n=73)\end{array}$ \\
\hline No fixed abode & 0 & $8^{*}$ & 16 \\
Hostel & 3 & 4 & 23 \\
Staffed home & 1 & 0 & 2 \\
Relatives & 4 & 2 & 11 \\
On own & 3 & 9 & 20 \\
Other & 0 & 0 & 1 \\
\hline
\end{tabular}

${ }^{*} P<0.05$

Data on age, sex, length of history, legal status, compliance with depot medication, accommodation and length of admission were collected prospectively from the patients and ward staff. In this study non-compliance is defined as a failure to take prescribed depot medication for a period between two weeks and one year prior to admission. The data were analysed by Fisher's exact test (two-tailed) and $t$ test as appropriate.

\section{Findings}

Seventy-three schizophrenic patients were admitted in total, of whom 34 had been prescribed depot medication. Of these, 23 (68\%) had stopped taking depot medication prior to admission. The average age of patients was 37.2 years for the whole study sample with no significant differences between the groups. Of the noncompliant patients, $20(87 \%)$ were admitted under a section of the Mental Health Act compared with only three (27\%) of the compliant patients $(P=0.0022)$. Table 1 details the accommodation from which the patients were admitted. The noncompliant patients were more likely to be of no fixed abode compared with those in receipt 
of their depot $(P=0.054)$. The non-compliant patients had an average length of admission of 71 days compared with 36 days for those who were compliant with depot $(P<0.05)$ and 66 days for the whole group. Length of past psychiatric history averaged 11.8 years for the whole sample, with no significant differences between the groups. The non-compliant patients were predominantly male (15 out of 23), the compliant patients female (6 out of 11 ). The average length of non-compliance with depot medication was 6.4 months.

\section{Comment}

The small sample size inevitably limits some of the conclusions that may be drawn from the study. We restricted the field of study to depot medication alone as a patient is either in receipt of it or not. Compliance with oral medication is more difficult to ascertain. The non-compliant patients were almost invariably admitted under a section of the Mental Health Act, probably reflecting a general unwillingness to accept treatment. They also spent longer in hospital. Eight of the non-compliant patients were of no fixed abode, possibly delaying discharge. A recent review Scott (1993) highlights the 30-50\% prevalence of functional mental illness among the homeless and the inherent difficulties in delivering effective care to this group.

A number of reasons for non-compliance have been put forward including extrapyramidal side effects, a poor doctor-patient relationship and a preference to retain schizophrenic symptoms, especially grandiose delusions (Van Putten et al, 1976). Most of our patients stopped because they felt they did not need it. The non-compliant patients in our study tended to be more likely to be living away from relatives and of no fixed abode. These characteristics, together with poor treatment compliance, emerged as the major determinants by which consultant psychiatrists would recommend compulsory community treatment, if it were to exist (Sensky et al, 1991). We cannot be sure of the significance of noncompliance to relapse in our patients as we do not know the figures for compliance and noncompliance without relapse in the population from which our patients were drawn. However, a recent study of 58 patients attending depot clinics in an inner London borough, points to the extent of non-compliance in this group (Sandford, 1994). Fifty per cent of patients were readmitted to hospital over 12 months. There was a positive correlation between readmission and number of injections missed with all 58 patients having missed at least one during the year.

The characteristics associated with noncompliance are likely to make an independent contribution to relapse but it remains probable that more professional effort directed at securing compliance could have prevented some of these.

In our study, non-compliance was associated with homelessness, a longer hospital stay and compulsory readmission. We feel that these findings strengthen the argument for a community supervision order. Such a measure, together with greater attention focused on the accommodation needs of this group, could help reduce relapse and the consequent pressure on in-patient facilities. Resources would be released that could be used to increase the quality of life of these patients in the community.

\section{Acknowledgements}

We wish to thank the wards concerned and Sylvia Mannering of medical records for their help.

\section{References}

BLUGLASS, R. (1992) Editorial. Maintaining the treatment of mentally ill people in the community. British Medical Journal, s08, 159-60.

- (1993) Editorial. New powers of supervised discharge of mentally ill people. British Medical Journal, 307, 1160.

GreEN, J.H. (1988) Frequent rehospitalization and noncompliance with treatment, hospital and community psychiatry. Hospital and Community Psychlatry. $\mathbf{3 9}$, 963-966.

LEFF, J. and WING. J.K. (1971) Trial of maintenance therapy in schizophrenia. British Medical Journal, III, 599-604.

SANDFORD. T. (1994) Users' perceptions of clinics providing depot phenothiazine treatments. In Current Perspectues in Mental Health Nursing (eds T. Sandford \& K. Gournay). Scutari. (In press).

SCOTT, J. (1993) Homelessness and mental illness. British Journal of Psychiatry, 162, 314-324.

SENSKY, T. et al (1991) Compulsory psychiatric treatment in the community. II. A controlled study of patient whom psychiatrists would recommend for compulsory treatment in the community. British Journal of Psychiatry. 168, 799-804.

VAN PUTTEN. T. et al (1976) Drug refusal in schizophrenia and the wish to be crazy. Archives of General Psychiatry. 33, 1443-1446.

J.D. Gardner, Senior Registrar; and O.W. Hill, Consultant Psychiatrist, St Luke's Woodside Hospital, London N10 $3 \mathrm{HU}$ 